1 ANALYTICAL SCIENCE

4 \& TECHNOLOGY

Vol. 26, No. 1, 80-85, 2013

http://dx.doi.org/10.5806/AST.2013.26.1.080

\title{
Study on the analytical method using GC-MS for the accident preparedness substances
}

\author{
Kijoon Kim, Jinseon Lee, Suyeong Lee, Seungryul Hwang, Younghee Kim and Gwangseol Seok ${ }^{\star}$ \\ Chemicals Research Division, National Institute of Environmental Research, \\ Environmental Research Complex, Incheon 404-708, Korea \\ (Received October 26, 2012; Revised December 19, 2012; Accepted February 4, 2013)

\section{실험실 GC-MS를 이용한 사고대비물질 분석방법 연구 \\ 김기준 · 이진선 · 이수영 · 황승률 · 김영희 · 석광설ᄎ \\ 국립환경과학원 화학물질연구과 \\ (2012. 10. 26. 접수, 2012. 12. 19. 수정, 2013. 2. 4. 승인)}

\begin{abstract}
The sixty nine accident preparedness substances (APS) having high probability of chemical accident are controlled under the Toxic Chemicals Control Act (TCCA). Around the world, there has been a growing interest in the analysis of chemical warfare agent (CWAs). When a chemical accident occurs, it is generally required to detect and identify APS. However, the quantitative analytical data remain limited in Korea. In this study, an analytical method using GC/MS for volatile organic chemicals was established and a quantitative analysis method was studied. The calibration curve for 25 chemicals were obtained and 21 chemicals showed higher coefficient of determination $\left(r^{2}>0.998\right)$.

요 약: 본 연구는 유해화학물질관리법에 지정되어 있는 사고대비물질에 대한 실험실적 분석방법을 정 립하기 위한 것으로, $\mathrm{GC} / \mathrm{MS}$ 분석이 가능한 25 종 사고대비물질을 대상으로 정량분석을 수행하였다. $\mathrm{GC/}$ $\mathrm{MS}$ 정량분석결과 69종 사고대비물질 중 산화프로필렌(propylene oxide) 등 21개 물질에 대한 결정계수 $\left(\mathrm{r}^{2}\right)$ 는 0.998 이상을 보였고, 포스겐(phosgene)의 결정계수는 0.994 , 노말-부틸아민(n-butyl amine) 외 1종은 0.987, 에틸렌디아민(ethylene diamine)은 0.958 의 결정계수를 보였다. 동일한 GC/MS 분석 조건으로 표준 물질을 분석한 결과 총 25 종에 대한 검량선이 작성되었다. 현재 사고대비물질에 대한 분석 연구가 필요 한 상황에서, 본 연구결과는 화학사고 사후 환경 영향 조사를 위한 정량분석에 도움이 될 것으로 판단된다.
\end{abstract}

Key words: accident preparedness substances (APS), GC/MS, quantitative analysis, phosgene, CWAs

\section{1. 서 론}

유해화학물질 사고대비물질은 급성독성(急性毒性) •
폭발성 등이 강해 사고발생의 가능성이 높거나 사고 가 발생 시 그 피해 규모가 클 것으로 우려되는 화학 물질로 총 69 종이 유해화학물질관리법(제2조, 제38조)

Corresponding author

Phone : +82-(0)32-560-7190 Fax : +82-(0)32-560-2039

E-mail : ksseok@korea.kr 
에 지정되어 관리되고 있다. ${ }^{1}$ 사고대비물질은 다음의 4가지 특성을 가진 물질들로, (1) 인화성, 폭발 및 반 응성, 누출 가능성 등 물리 - 화학적 위험성이 높은 물 질, (2) 경구(經口) 투입, 흡입 또는 피부에 노출될 경 우 급성독성이 큰 물질, (3) 국내 유통량이 많아 사고 노출 가능성이 높은 물질, (4) 그 밖에 사고발생 우려가 높아 특별한 관리가 필요하다고 인정되는 물질이다.

69 종 사고대비물질의 사고 - 테러 위험유형은 크게 화재 - 폭발위험, 독성 위험, 노출 가능 위험, 불법전용 위험으로 분류된다. 화재 - 폭발 위험이 높은 물질로는 미국방제협회(National Fire Protection Agency, NFPA) 의 위험물 확인기준에 의해 알릴클로라이드(allyl chloride), 아크릴로니트릴(acrylonitrile), 이황화탄소 (carbon disulfide), 산화프로필렌(propylene oxide) 등 31 종이 해당되고, 환경오염을 유발하는 물질과 인체 에 심각한 위험을 미치는 화학물질은 폼알데하이드 (formaldehyde), 포스겐(phosgene) 등 21 종, 유통량이 많아 노출위험이 높은 물질은 염화수소(hydrogen chloride)와 황산(sulfuric acid), 탈취 및 전용이 가능한 물질은 니트로메탄(nitromethane), 과산화수소(hydrogen peroxide) 등 15 종이 해당된다. ${ }^{2}$

화학사고 또는 테러 발생 시 신속한 대응을 하기 위해서는 물질에 대한 정성적인 정보가 우선적으로 필요하다. 현장에서 신속하고 정확한 측정을 하기 위 해서 GC/MS (gas chromatography mass spectrometry) FT-IR (fourier transform infrared spectrometer) 분광계, $\mathrm{XRD}$ (X-ray diffractometer)등의 휴대용 장비가 활용된 다. ${ }^{3}$ 현장에서 신속한 탐지분석 이후에도 현장에서의 사고대비물질에 대한 환경농도 평가 및 잔류농도 평 가를 하기 위해서는 정밀한 실험실 분석 방법이 필요 하다.

사고대비물질에 대한 실험실 분석방법은 미국 $\mathrm{EPA}$ (Environmental Protection Agency), OSHA (Occupational Safety and Health Administration), NIOSH (National Institute Of Occupational Safety \& Health) 등 국외 문 헌과 국내 대기오염공정시험기준, 수질오염공정시험 기준, 유해화학물질공정시험기준 등 국내 시험기준 자 료에서 찾아볼 수 있다. $\mathrm{EPA}$ 에서는 물질별 시료채취 방법 및 분석기기를 이용한 분석방법을 제시하고 이 용목적에 따라 시험방법을 분류하고 있으며, 사고대비 물질 중에서는 총 33 종에 대한 시험방법을 제시하고 있다. ${ }^{4-5} \mathrm{OSHA}, \mathrm{NIOSH}$ 에서는 흡착관을 이용하여 시 료를 채취하고 용매 추출한 후 물질 특성에 따라 여 러 가지 검출기로 분석하는 방법을 제시하고 있다. ${ }^{11-12}$
OSHA에서는 사고대비물질 16 종, $\mathrm{NIOSH}$ 에서는 사 고대비물질 13 종에 대한 분석방법을 제시하고 있다. 국내 공정시험방법 중 대기오염공정시험방법, 수질오 염공정시험방법, 유해화학물질공정시험방법, 먹는물수 질공정시험방법, 토양오염공정시험방법을 조사한 결 과 환경 중 대상물질을 분석하기 위하여 $\mathrm{HPLC}, \mathrm{AA}$, $\mathrm{GC} / \mathrm{MS}, \mathrm{GC}-\mathrm{FID} / \mathrm{FPD} / \mathrm{ECD} / \mathrm{PID} / \mathrm{TCD}$ 등 다양한 검출 방법과 분석조건이 제시되어 있다. 특히, 국내외 - 적으 로 벤젠, 톨루엔, 포름알데하이드 등과 같은 기존부터 연구가 많이 되던 물질에 대한 분석방법은 다양하게 제시되고 있는 반면, 다른 사고대비물질에 대한 분석 자료는 제한적이다. 대부분의 물질들이 다른 매체 분 석을 위해 시험방법이 개발되어 있으므로 다양한 방 법의 분석방법이 제안되고 있다. 화학사고 발생 시 신 속하게 대응하기 위해서는 사고대비물질에 맞는 시료 채취 방법 및 분석방법 개발이 필요하다.

일반적으로 화학물질에 대한 정성적인 정보를 얻기 위하여 GC-MS가 유용하게 사용된다. ${ }^{6-10} \mathrm{MSD}$ (mass selective detector) 검출방식은 화학물질의 고유한 분 해 패턴에 의해서 물질의 정성확인이 가능한 방식으 로 미지물질의 정성확인 방법에 유용하게 사용될 수 있다. 이러한 특성 때문에 Kientz 등과 Kimm 등의 연 구자들은 화학작용제(chemical warfare agents, CWAs) 를 분석하는데 GC/MS를 사용하여 왔다. ${ }^{6-7}$ HooiJschuur 등의 연구자는 화학작용제를 분석하는데 물질들의 물 성 특성에 따라 $\mathrm{GC} / \mathrm{MS}, \mathrm{LC} / \mathrm{MS}, \mathrm{GC}-\mathrm{GC} / \mathrm{MS}$ 등의 다 양한 분석장비를 제안하였다. ${ }^{8}$

국내에서 화학사고나 테러 발생 시 이에 대한 신 속하고 체계적인 대응을 하기 위해서는 사고대비물 질에 대한 현장에서의 정성 분석 뿐 아니라 정량 분 석도 필요하다. 본 연구에서는 사고대비물질을 $\mathrm{GC} /$ $\mathrm{MS}$ 를 이용하여 분석하는 방법에 대하여 연구하고, $\mathrm{GC} / \mathrm{MS}$ 로 분석 가능한 물질에 대하여 정량적으로 평가하였다.

\section{2. 실험방법}

\section{1. 분석용 표준물질 제조 방법}

분석용 표준물질을 제조하기 위하여 Table 1과 같 이 순도 높은 표준 시약을 Sigma-aldrich, Junsei, Osaka로부터 구매하였고, 일부 물질은 용매에 녹아있 는 시약을 구매하였다. 분석하고자 하는 물질의 특성 을 고려하고 용매와의 피크 겹침 현상을 피하기 위하 여 dichloromethane (DCM) 용매와 toluene (TOL) 용매 
Table 1. Analytical standard materials

\begin{tabular}{|c|c|c|c|c|}
\hline No. & Chemicals & Manufacturer & Purity & Solvent \\
\hline 1 & Formaldehyde & SIGMA & $30 \%$ in methanol & MET \\
\hline 2 & Methanol & SIGMA & $99.93 \%$ & TOL \\
\hline 3 & Phosgene solution & Junsei & $20 \%$ in toluene & TOL \\
\hline 4 & Propylene oxide & SIGMA & $99.70 \%$ & TOL \\
\hline 5 & Acrylonitrile & OSAKA & $99 \%$ & TOL \\
\hline 6 & Allyl chloride & SIGMA & $99 \%$ & TOL \\
\hline 7 & Carbon disulfide & SIGMA & $99 \%$ & TOL \\
\hline 8 & Allyl alcohol & SIGMA & $99 \%$ & TOL \\
\hline 9 & Methyl vinyl ketone & SIGMA & $99 \%$ & TOL \\
\hline 10 & Methyl ethyl ketone & Junsei & $99 \%$ & TOL \\
\hline 11 & Ethyl acetate & SIGMA & $99.80 \%$ & TOL \\
\hline 12 & Acrylic acid & SIGMA & $99 \%$ & TOL \\
\hline 13 & Methyl acrylate & SIGMA & $99 \%$ & TOL \\
\hline 14 & Nenzene & Junsei & $99.70 \%$ & DCM \\
\hline 15 & Toluene & Junsei & $99.50 \%$ & DCM \\
\hline 16 & Phenol & SIGMA & $99 \%$ & DCM \\
\hline 17 & Benzyl chloride & SIGMA & $99 \%$ & DCM \\
\hline 18 & m-cresol & SIGMA & $98 \%$ & DCM \\
\hline 19 & Nitrobenzene & SIGMA & $99.70 \%$ & DCM \\
\hline 20 & p-nitrotoluene & SIGMA & $98 \%$ & DCM \\
\hline
\end{tabular}

를 사용하였고, methanol 용액에 포함된 표준시약은 methanol (MET) 용매에 희석하여 사용하였다. 표준용 액은 일정 부피의 용매에 분석하고자 하는 물질을 질 량기준으로 첨가하여 일정농도의 표준용액을 제조하 였다. $\mathrm{GC}$ 주입 부피인 $1 \mu \mathrm{L}$ 를 기준으로 분석대상물 질의 질량을 계산하였고, 낮은 질량인 level 1 부터 높 은 질량인 level 5 까지 질량 단계별 표준용액을 제조 하였다.

제조과정에서 발생되는 표준용액의 오차를 확인하 기 위하여 농도 단계별로 중복표준용액(duplicate standard solution)을 제조하여 각각 분석하였고, 분석 결과 중복표준용액의 편차는 평균 $10 \%$ 이내로 나타 났다.

끊는점이 $-13.3{ }^{\circ} \mathrm{C}$ 와 $-23.7{ }^{\circ} \mathrm{C}$ 로 매우 낮은 염화비 닐(vinyl chloride)과 염화메틸(methyl chloride)은 표준 가스(100 ppm, Rigas, Korea)를 구매하여 농도별 표준 가스를 제조 한 후 $100 \mu \mathrm{L}$ 부피를 기체상태로 $\mathrm{GC} /$ MS로 주입하여 분석하였다.

\section{2. 분석방법 및 조건}

사고대비물질 표준물질 분석을 위해서 $\mathrm{GC} / \mathrm{MS}$ (Agilent 6890/5973)가 사용되었고, 컬럼은 DB-5MS $(30 \mathrm{~m}, 0.25 \mathrm{~mm}, 0.25 \mu \mathrm{m})$ 가 사용되었다. GC/MS 분
Table 2. Analytical parameters of laboratory GC/MS

\begin{tabular}{|c|c|c|c|}
\hline Parameters & \multicolumn{3}{|c|}{ Conditions } \\
\hline & \multicolumn{3}{|l|}{ Split ratio - 10:1 } \\
\hline Injector condition & \multicolumn{3}{|c|}{ Temperature $-230{ }^{\circ} \mathrm{C}$} \\
\hline & \multicolumn{3}{|c|}{ Injection Volume - $1 \mu \mathrm{L}$ (liquid) } \\
\hline Column flow & \multicolumn{3}{|l|}{$1 \mathrm{~mL} / \mathrm{min}$} \\
\hline \multirow[t]{4}{*}{ Oven program } & Rate $\left({ }^{\circ} \mathrm{C} / \mathrm{min}\right)$ & Temp. $\left({ }^{\circ} \mathrm{C}\right)$ & Time (min) \\
\hline & & 35 & 5 \\
\hline & 5 & 80 & 0 \\
\hline & 10 & 300 & 0 \\
\hline
\end{tabular}

석 조건은 Table 2와 같고, 표준용액을 Auto-sampler 을 이용하여 $1 \mu \mathrm{L}$ 주입하였다.

Scan mode에서 20 200 amu 범위로 각 표준물질의 질량스펙트럼을 확인하고, 각 물질별 정량이온을 선택 하여 선택이온검색법(Selected Ion Monitoring, SIM)으 로 검량선을 작성하였다. 물질의 체류시간(retention time)이 겹치고 선택정량이온이 유사한 경우 서로 겹 치지 않는 이온을 정량이온으로 선택하였다(Table 3).

\section{3. 결과 및 고찰}

사고대비물질 69 종 중 물성 특성을 고려하고 화학 
Table 3. Quantum ion of chemical substances

\begin{tabular}{|c|c|c|c|c|c|}
\hline Chemicals & Q.ion (1) & Q.ion (2) & Chemicals & Q.ion (1) & Q.ion (2) \\
\hline Formaldehyde & 29 & 30 & Ethyl acetate & 61 & 43 \\
\hline Methanol & 31 & 32 & Acrylic acid & 72 & 27 \\
\hline Phosgene & 63 & 65 & Methyl acrylate & 55 & 85 \\
\hline Propylene oxide & 58 & 28 & Benzene & 78 & 77 \\
\hline Acrylonitrile & 53 & 26 & Toluene & 91 & 92 \\
\hline Allyl chloride & 41 & 39 & Phenol & 94 & 66 \\
\hline Carbon disulfide & 76 & 44 & Benzyl Chloride & 91 & 126 \\
\hline Allyl alcohol & 57 & 31 & m-Cresol & 108 & 107 \\
\hline Methyl vinyl ketone & 55 & 43 & Nitrobenzene & 77 & 123 \\
\hline Methyl ethyl ketone & 29 & 72 & p-Nitrotoluene & 91 & 137 \\
\hline
\end{tabular}

테러 물질 등 수입이 어려운 시약을 제외하여 28 종 을 대상으로 동일한 조건으로 분석하였다. 그중에서 사고대비물질 26 종은 용매에 희석하여 분석하였고, 2 종은 가스상으로 주입하여 분석하였다. 폼알데하이드 (formaldehyde)와 메탄올(methanol)과 같이 분자량이 작고 끓는점이 낮은 물질은 체류시간(retention time, $\mathrm{RT}$ )이 2.539 분과 2.731 분으로 앞쪽에서 검출되었고, 분자량이 크고 끓는점이 높은 파라-나이트로톨루엔(pnitrotoluene)은 20.14 분으로 뒤쪽에서 검출되었다.

$\mathrm{GC}$ 주입량을 기준으로 검량선을 작성한 결과 20 개 사고대비물질에 대한 검량선 작성결과가 검출 순서대
로 Table 4에 제시되어 있다. 사고대비물질 20 종 중 17 종은 결정계수 $\left(r^{2}\right)$ 가 0.999로 우수한 직선성을 보였다. 아크릴산(acrylic acid)과 폼알데하이드(formaldehyde)의 결정계수 $\left(\mathrm{r}^{2}\right)$ 는 0.998 로 나타났고, 포스겐(phosgene)은 0.994 로 나타났다.

Fig. 1에 20 개 사고대비물질에 대한 검량선 그래프 가 나타나 있다. Fig. 1 왼쪽 상단의 벤젠고리를 포함 한 7 개 물질의 검량선을 보면 유사한 특성을 나타내 며 물질에 따라서 기울기가 다름을 알 수 있다. 20 개 사고대비물질 중 폼알데하이드의 검 량선 기울기 값 (slope)은 가장 작은 값(113)으로 다른 물질에 비해서

Table 4. Calibration equation and correlation of determination by laboratory GC/MS

\begin{tabular}{|c|c|c|c|c|c|}
\hline Chemicals & Slope (a) & Constant (b) & $\mathrm{r}^{2}$ & M.W. & B.P. $\left({ }^{\circ} \mathrm{C}\right)$ \\
\hline Formaldehyde & 113 & 36,845 & 0.998 & 30.0 & -19.5 \\
\hline Methanol & 6,124 & 347,982 & 0.999 & 32.0 & 64.7 \\
\hline Phosgene & 1,841 & 37,179 & 0.994 & 98.9 & 179.0 \\
\hline Propylene oxide & 5,078 & 500,142 & 0.999 & 58.1 & 34.2 \\
\hline Acrylonitrile & 10,899 & $1,694,910$ & 0.999 & 53.1 & 77.3 \\
\hline Allyl chloride & 6,221 & 173,770 & 0.999 & 76.5 & 45.0 \\
\hline Carbon disulfide & 4,202 & 257,843 & 0.999 & 76.1 & 46.5 \\
\hline Allyl alcohol & 12,999 & 234,386 & 0.999 & 58.1 & 96.0 \\
\hline Methyl vinyl ketone & 1,924 & (-) 201,582 & 0.999 & 70.1 & 81.4 \\
\hline Methyl ethyl ketone & 3,440 & 146,321 & 0.999 & 72.1 & 79.6 \\
\hline Ethyl acetate & 2,572 & 891,090 & 0.999 & 88.1 & 77.0 \\
\hline Acrylic acid & 1,642 & 570,029 & 0.998 & 72.1 & 141.0 \\
\hline Methyl acrylate & 2,733 & (-) 80,482 & 0.999 & 86.1 & 80.5 \\
\hline Benzene & 5,800 & 9,795 & 0.999 & 78.1 & 80.1 \\
\hline Toluene & 6,188 & (-) 50,939 & 0.999 & 92.1 & 110.6 \\
\hline Phenol & 4,246 & $(-) 88,749$ & 0.999 & 94.1 & 181.8 \\
\hline Benzyl Chloride & 5,041 & (-) 107,092 & 0.999 & 126.9 & 179.0 \\
\hline m-Cresol & 3,663 & (-) 103,629 & 0.999 & 108.1 & 202.0 \\
\hline Nitrobenzene & 2,845 & (-) 84,582 & 0.999 & 123.1 & 211.0 \\
\hline p-Nitrotoluene & 2,407 & $(-) 92,636$ & 0.999 & 137.1 & 238.0 \\
\hline
\end{tabular}

Vol. 26, No. 1, 2013 

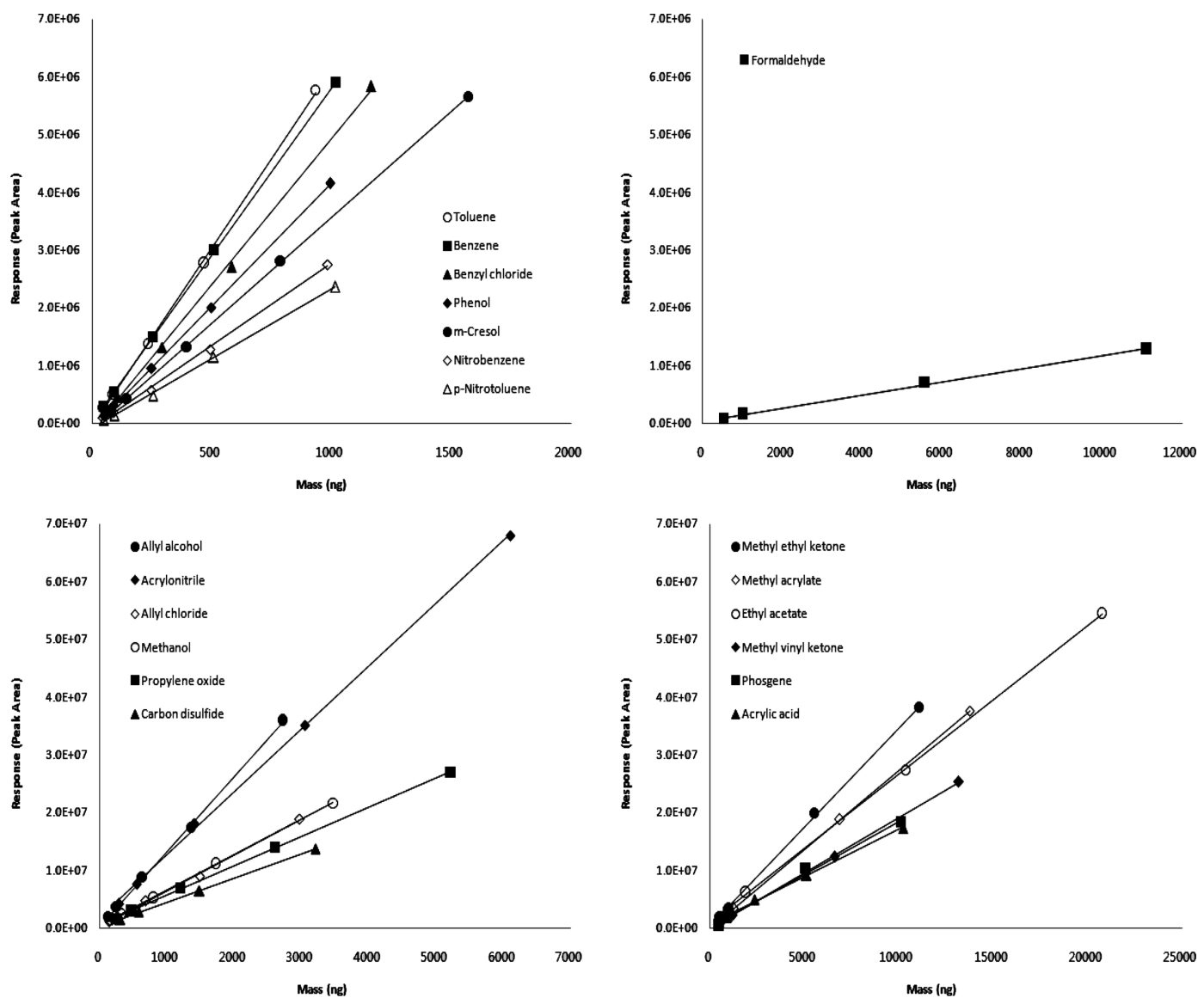

Fig. 1. Calibration curve for 20 APSs by GC/MS.

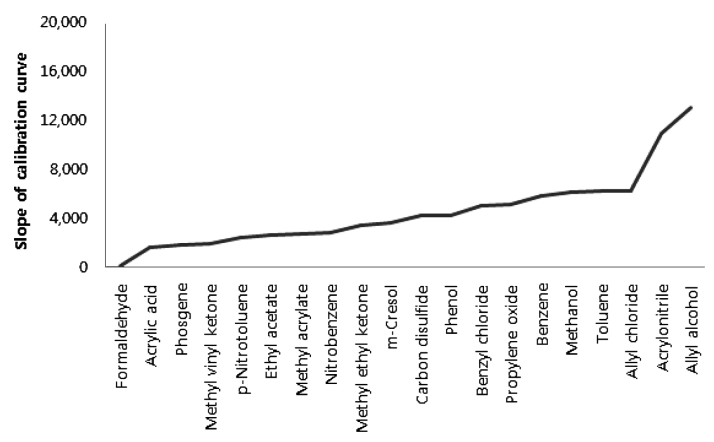

서 상대적으로 높았다. 아크릴로나이트릴(acrylonitrile) 의 중복표준용액 분석의 level $2 \sim 5$ 번 편차가 $3 \%, 3 \%$, $6 \%, 2 \%$ 로 양호한 결과를 보인 반면, 질량이 낮은 level 1 번 용액은 $12 \%$ 로 상대적으로 큰 편차를 보였 다. 또한, level 3번 표준용액이 상대적으로 높은 감도 (response)를 보였기 때문에 절편 값이 양의 방향으로 일부 편향된 것으로 판단된다.

20 개 물질 이외에도 노말-부틸아민(n-butyl amine), 에 틸 렌디아민(ethylene diamine), 트리에 틸아민(triethyl amine)을 $\mathrm{GC} / \mathrm{MS}$ 로 검량선을 작성한 결과 결정계수가 0.987 $(\mathrm{a}=4,143, \quad \mathrm{~b}=(-) 1,288,447), \quad 0.958(\mathrm{a}=1,376, \quad \mathrm{~b}=$ $(-) 73,138), 0.988(\mathrm{a}=32,984, \mathrm{~b}=2,128,813)$ 로 상대적으 로 낮게 나타났다. 이러한 현상은 이들 물질들이 현재 $\mathrm{GC}$ 조건에서 피크 끌림 현상을 보이고, 중복표준용액 분석 편차가 평균 $30 \%$ 정도로 높게 나타났기 때문인 것으로 판단된다. 향후 이들 물질들에 대해서는 추가 적인 분석 조건 확립이 필요할 것으로 판단된다. 
아크릴산(acrylic acid), 아크릴로나이트릴(acrylonitrile), 에틸아세테이트(ethyl acetate), 산화프로필렌(propylene oxide)에서 level 1 의 response 값이 검 량 추세선에서 일부 벗어나고 상대적으로 높은 절편 값을 보여주었 다. 이는 검량선 그래프에 보이는 바와 같이 level 2 또는 level 3 포인트가 추세선에서 일부 양의 방향으 로 벗어나면서 절편이 양의 방향으로 편향되었기 때 문에 질량이 가장 낮은 level 1 포인트가 검량 추세선 에서 벗어나 보이는 것으로 판단된다. 또한 에틸아세 테이트(ethyl acetate)의 중복표준용액 분석 결과 약 $25 \%$ 의 큰 편차를 보였고, 아크릴산(acrylic acid)은 level 5 가 $26.1 \%$ 편차, level 1 이 $17.9 \%$ 편차를 보였다. 아크릴로나이트릴(acrylonitrile)은 level 1이 11.9\% 편 차, 산화프로필렌(propylene oxide)은 level 2가 $10.8 \%$ 편차를 보이면서 추세선에 영향을 미친 것으로 판단 된다.

끓는점이 $-13.3{ }^{\circ} \mathrm{C}$ 와 $-23.7{ }^{\circ} \mathrm{C}$ 로 매우 낮은 염화비 닐(vinyl chloride)과 염화메틸(methyl chloride)은 기체 상태로 주입하였고, 결정계수는 $0.999(\mathrm{a}=16,037, \mathrm{~b}=$ $2,087)$ 와 0.999( $\mathrm{a}=17,109, \mathrm{~b}=(-) 17,570)$ 로 확인되었다.

아크롤레인(acrolein), 삼염화인(phosphorus trichloride), 옥시염화인(phosphorus oxychloride), 포름산(formic acid), 아크릴일 클로라이드(acrylyl chloride), 나이트로 메탄(Nitromethane)은 $\mathrm{GC} / \mathrm{MS}$ 를 이용하여 정성적으로 분석 가능한 것으로 보고되었으나(노혜란 등, 2012), 본 연구에서는 시약을 확보하지 못해 정량실험을 수 행하지 못하였다. 향후 추가적으로 표준시약을 확보 한 후 $\mathrm{GC} / \mathrm{MS}$ 를 이용한 정량분석 확인을 추진할 계획 이다.

\section{4. 결 론}

본 연구는 유해화학물질관리법에 지정되어 있는 사 고대비물질에 대한 실험실적인 분석방법을 정립하기 위한 것으로, 특히 $\mathrm{GC} / \mathrm{MS}$ 를 이용하여 동일한 조건에 서 정량방법 연구를 수행하였다. 69 종 사고대비물질 중 산화프로필렌(propylene oxide) 등 21 개 물질에 대 한 $\mathrm{GC} / \mathrm{MS}$ 정량 분석 결과 결정계수 $\left(\mathrm{r}^{2}\right) 0.998$ 이상을 보였고, 포스겐(phosgene)의 결정 계수는 0.994, 노말부틸아민(n-butyl amine) 외 1 종은 0.987 , 에틸렌디아 민(ethylene diamine)은 0.958 의 결정계수를 보였다. 동일한 $\mathrm{GC} / \mathrm{MS}$ 분석 조건으로 총 25 종에 대하여 정 량이 가능하였다. 본 연구결과는 화학사고 사후 환경 영향 조사를 위한 정량분석에 도움이 될 것으로 판단 된다. 향후 $\mathrm{GC} / \mathrm{MS}$ 를 이용한 추가적인 정량적 분석방 법에 대한 연구가 필요하며, 사고대비물질 이외에 화 학작용제(CWAs)에 대한 체계적인 연구도 추진되어야 한다. 또한, $\mathrm{GC} / \mathrm{MS}$ 이외의 가스상, 액상, 고상 물질들 에 대한 정성적 또는 정량적 분석 연구가 지속적으로 수행되어야 한다.

\section{참고문헌}

1. 환경부 유해화학물질관리법 (2010).

2. 환경부, 사고대비물질 영업자 관리 및 취급시설 기 준 연구 (2010).

3. 노혜란, 이진선, 김정민, 김기준, 석광설, 한국환경분 석학회지, 15(1), 27-34 (2012).

4. EPA ORD NHSRC(a), Rapid screening and preliminary identification techniques and methods, EPA/600/ R-10/090 (2010).

5. EPA ORD NHSRC(b), Sample collection information document, EPA/600/R-09/074 (2010).

6. Ch. E. Kientz, J. Chromatogr. A, 814, 1-23 (1998).

7. G. L. Kimm, G. L. Hook and P. A. Smith, J. Chromatogr. A, 971, 185-191 (2002).

8. E. W. J. Hooijschuur, C. E. Kientz and U. A. Th. Brinkman, J. Chromatogr. A, 982, 177-200 (2002).

9. P. A. Smith, C. J. Lepage, M. Lukacs, N. Martin, A. Shufutinsky and P. B. Savage, Int. J. Mass Spectro., 295(3), 113-118 (2010).

10. J. R. Hancock, C. R. Jackson Lepage, C. L. Chenier, D. S. W. Froese and M. J. Lukacs, On-Site Chemical Warfare Agent Identification, Defence R\&D Canada. (2007).

11. U. S. Department of Labor, OSHA Analytical Methods.

12. U. S. Department of Healty and Human Services (US DHHS), NIOSH Manual of Analytical Methods (1994). 